Title:

\title{
Assessment as the site of power: A Bourdieusian interrogation of service user and carer involvement in the assessments of social work students
}

\begin{abstract}
The centrality of service user and carer involvement in social work education in England is now well established, both in policy and practice. However, research evidence suggests their involvement in student assessments is underdeveloped and under researched. This study focused on the positioning of service users and carers in relation to other stakeholders involved in the assessments of social work students in England. Using narrative research methodology, 21 participants, including service users, carers, social work students, social work employers and social work educators, were offered a semi-structured individual interview. Participants' narratives revealed different power relations among those involved in social work students' assessments and a lack of confidence among service users and carers in making failed assessment recommendations. The paper concludes by arguing the case for social work educators and service user organisations to provide joint training to support service users and carers in their role as assessors of social work students.
\end{abstract}

Keywords: Service user involvement; Carer involvement; Students assessments; Social work education; Bourdieu

\section{Introduction}

Service user and carer involvement in social work education in the UK is well established. However, research indicates that service users and carers occupy a less powerful position than academics in their role as assessors (Stickley et al., 2011). Skoura-Kirk et al.'s (2013) study reported that whilst service users and carers are included as major stakeholders in social work student assessments, their actual involvement in assessments is peripheral. The less powerful position occupied by service users in social work education also appears to be an international issue. Askheim (2012) notes that although social work education in Norway has embraced the involvement of service users, they still do not participate on equal terms. Whilst the discourse and concept of service user and carer involvement is emerging from 
Scandinavian countries (Askheim, 2012; Kvarnström et al., 2012; 2013), this has not been adopted in the North American social work education literature. Indeed the Council on Social Work Education's Educational Policy and Accreditation Standards (CSWE, 2013) makes no reference to service users and carers, and does not make their participation an accreditation requirement. Similarly, although the concept of involvement is mentioned in the 2015 revised Australian Social Work Education and Accreditation Standards (ASWEAS) 2012 V1.4, ASWEAS does not make service user involvement in social work students' assessment an accreditation requirement. ASWEAS $(2012,5.1)$ suggests that where possible higher education providers should involve 'clients, service users and communities in the planning and delivery of social work education programs'.

This research was undertaken in England between 2010 and 2013 and focuses on the UK context. The research question was: 'What are stakeholders' experiences of the involvement of service users and carers in the assessment of social work students?' The study drew on the theoretical insights of Bourdieu's (1990) concepts of capital and doxa to analyse the dynamic power relations between the stakeholders involved. These concepts will be returned to later on in the paper.

\section{Clarifying terms}

It is essential first to briefly clarify terms for an international readership. The terms 'service user' and 'carer' are used here to refer to people with lived experiences of using both health and social care services, and who bring lay perspectives to the teaching, learning and assessment of students. Although there are debates about terminology (see for example Barnes and Cotterell, 2012; Beresford, 2013; McLaughlin, 2009; Taylor et al., 2009), the term 'service user', rather than client or other related terms, is used here because it is the term predominantly used in UK policy and practice and in the related literature. For brevity, we refer to 'service user' to include 'service user and carer'. Where appropriate, 'carer' is used.

It is also important to clarify the meaning of 'assessment'. Assessment has acquired an 'overwhelmingly powerful role in education' (Broadfoot, 1984, p.2). It has become a potent tool in dictating institutional and professional goals (Taylor, 1997). There is extensive 
literature on this topic, together with associated academic journals in the field of education. Whereas it is beyond the scope of this paper to explore this literature here, we briefly refer to two particular sources to illuminate later discussion. Boud (1996) suggests that assessment involves first the identification of standards which may apply to any given work, and secondly the capacity to make judgements about whether the work meets the required standards. Taylor (1997) draws on work differentiating assessment designed to be formative and to provide feedback to improve performance, and/or summative related to the judgement of that performance. 'In both cases, judgement is involved, but in the first it directly serves the needs of the student, and in the second it primarily serves the needs of the university and/or profession' (Taylor, 1997, p. 109). Assessment, including formative and summative feedback has a gatekeeping role in professional education such as social work by ensuring that educational and professional standards are maintained as well as preventing unsuitable candidates from entering the profession (Finch and Taylor, 2013). Service user and carer assessment feedback including formative and summative feedback and gatekeeping are interconnected.

\section{Policy background}

The requirement to involve service users in all aspects of social work education in England was previously initiated under Part IV, Sections 63 to 66 of the Care Standards Act 2000. The Health and Social Care Act 2012 Act amended the Care Standards Act 2000 (c. 14). Section 213 of the 2012 Act provided for the regulation of social work education by the Health and Care Professions Council (HCPC) in England. Since taking over this role in August 2010, the HCPC has placed emphasis on service user involvement (HCPC, 2012). In England, service users and carers are involved in providing both formative and summative assessment feedback on students practice and academic work (Wallcraft et al., 2012). These include assessing written readiness for practice, critical reflections and written elements of practice learning portfolios (Wallcraft et al., 2012).

\section{Literature review}


With the research question as the focus, publications to be included in the literature review were sought from Social Care Online (SCIE), SCOPUS and Applied Social Science Index Abstract (ASSIA) using the following keywords: 'service user involvement', 'carer involvement', 'service user AND students assessments', 'social work education' AND service user involvement'. The search focused on research studies published in English, undertaken in the UK and internationally between 2010 and spring 2013. It included nonpeer-reviewed literature and research referred to on UK service user organisations' websites (Social Work Education Participation (SWEP), Participation Compass, Shaping Our Lives and INVOLVE) about service user involvement in the assessments of social work students. As studies addressing service user involvement in social work students' assessments were limited, the literature search was extended to related professions such as nursing and medicine. A total of 287 references were identified, including duplications from Social Care Online, SCOPUS, and the Social Work Education Participation (SWEP) website. Fifteen papers met the inclusion criteria: Social Work Education: The International Journal $(\mathrm{n}=3)$, Social Care Online (n=3), Nurse Education Today $(\mathrm{n}=7)$, Innovations in Education and Teaching International $(\mathrm{n}=1)$ and Medical Education $(\mathrm{n}=1)$. Ten studies were conducted in England and the others originated from Scotland (2), the Netherlands, Northern Ireland and Belgium.

\section{Key themes from the literature review}

A limited number of studies was found on service user involvement in social work students' assessments (Chambers and Hickey, 2012; Duffy et al., 2013; Skilton, 2011; Skoura-Kirk et al., 2013; Wallcraft et al., 2012). Skoura-Kirk et al. (2013) examined service user involvement in the academic assessment of second year BA Social Work students and found that although service users were involved in the design and delivery of the module, the university regulations did not grant them the power to allocate final marks. Skoura-Kirk and colleagues highlighted some of the tensions and constraints faced by social work academics and service user assessors within HEI assessment systems and structures. This was consistent with Skilton's (2011) study which focused on the process of involvement of service users in social work students' assessments, where she reported that academics made the final decisions. Duffy et al.'s (2013) study focused on service user involvement in role-play presentations by first-year social work students. The findings indicated that both staff and 
students were mostly neutral or quite positive about involving service users in students' assessments. Wallcraft et al.'s (2012) study, commissioned by the Social Care Institute for Excellence (SCIE), reported that unlike other areas of social work education, service user involvement in students' assessments was underdeveloped. Wallcraft et al.'s (2012) findings also suggested that involvement in students' assessments on post-qualifying programmes (now known as Continuing Professional Development) was weak. Chambers and Hickey's (2012) study, commissioned by the HCPC, explored the involvement of service users in the design and delivery of pre-registration education and training programmes approved by the HCPC. They confirmed that involvement in students' assessments was underdeveloped (Chambers and Hickey, 2012).

Although it was beyond the scope of this study to explore patient involvement in health education more broadly, the studies in Nurse Education Today reported that, despite the growing body of literature on service user involvement in the medical and social care professions, there were only limited studies exploring their involvement in students' assessments (Dearnley et al., 2011; Debyser et al., 2011; Muir and Laxton, 2012; Stacey et al., 2012; Stickley et al., 2010). Muir and Laxton (2012) indicated that although service users have long been involved in the training of medical students, they play a passive role in assessments. This was echoed by Debyser et al. (2011), who concurred that although service users play a central role in psychiatric nursing, they are 'seldom formally' involved in providing feedback on student nurses' practice training assessments (p.198). Reinders and colleagues (2011) carried out a randomised controlled trial into the effectiveness of service user involvement in developing general practice trainees' communication skills in the Netherlands. The study did not provide conclusive evidence on whether service user involvement in students' assessments improved trainees' skills (Reinders et al., 2011).

As seen above, most of the papers reported involvement by means of providing feedback to assessments completed by others (Skilton, 2011; Skoura-Kirk et al., 2013). Webster et al. (2012) explored the experiences, views and evaluation of service user involvement in feedback to nursing students in Scotland using a clinical skills simulation scenario. These 
authors note the lack of criteria against which service users could make their assessment judgements.

\section{Methodology and ethics}

The study drew from the constructivist, interpretivist, participatory and practitionerresearcher paradigms (Drake and Heath, 2011; Patton, 2002). It is situated in the qualitative research tradition, drawing upon the narrative research approach. It was interested in identifying and understanding multiple layers of meaning within personal stories (Squire, 2008) and focuses on human interactions and relationships (Riessman and Quinney, 2005). The research participants were recruited from three institutions providing social work degree programmes and different social work practice sites. The sample group included service users $(n=3)$, carers $(n=2)$, social work students $(n=5)$, social work employers $(n=6)$ and social work educators $(n=5)$. The inclusion criterion focused on those with lived experience of service user involvement in social work students' assessments.

Ethical approval for the study was obtained through the Ethics Committee for the university where the first author was registered as a student. Ethics were considered from a practitionerresearcher position, both as an 'insider' and an 'outsider' (Mercer, 2007) and from the four binding ethical principles underpinning social research: beneficence, non-maleficence, respect for autonomy of persons, and justice (Boulton, 2009). Consent was sought both verbally and in a written format through an informed process consent procedure, rather than a one-off informed consent procedure (Houghton et al., 2010). Confidentiality and anonymity were addressed in relation to individual participants and the sites from which they were drawn.

The data were collected through semi-structured, individual face-to-face interviews. Withinmethod data source triangulation was used to allow multiple voices and stakeholder perspectives to be heard (Patton, 2002). Data source triangulation refers to the process where more than one data source is used in the same research design, either for confirmation or 
completeness of the data (Patton, 2002). Data source triangulation involving interviews with different sample groups (social work employers, social work students, service users, carers and social work educators), was used for completeness. An interview guide was developed, following consultations with different stakeholders involved in social work students' assessments. A total of 21 individual face-to-face semi-structured interviews were undertaken. The research participants were asked to share their experiences of service user and carer involvement in social work students' assessments, and on how they felt service users and carers were positioned in relation to others in this role. The interviews were audiorecorded and transcribed verbatim. No interview lasted more than an hour; further considerations were made for a shorter interview time for service users to ensure they were not unduly tired.

The interview data was analysed using the voice-centred relational method developed by Gilligan and colleagues (Brown and Gilligan, 1992; Gilligan, 1982; Taylor et al., 1995). The method is underpinned by relational ontology. It allows individuals' stories to be understood within their relationships with others in the broader social, political, cultural and structural context in which they live (Fairtlough et al., 2013; 2013a; Mauthner and Doucet, 1998; Taylor et al., 1995). The approach recognises the central role of the researcher in the coproduction of knowledge (Taylor et al., 1995). The main tenet of the voice-centred relational method of data analysis consists of four different readings of each interview data to identify: “(1) Who is speaking? (2) In what body? (3) Telling what story about the relationship - from whose perspective or vantage point? (4) In what societal and cultural frameworks?" (Brown and Gilligan, 1992, p.21).

Following four readings of each interview, the scrutiny-based technique developed by Ryan and Bernard (2003) was used to identify and develop themes. This involved combing through each interview transcript for: repeated concepts or recurrent expressions relating to the research question; issues similar to those identified from the literature review; and observations from practice as an 'insider'. Both salient expressions as well as missing information were identified in the process. Highlighters on Microsoft Word were used to colour-code salient recurring expressions which addressed the research question; issues similar to those identified from the literature review; practice and issues which fell within the 
theoretical framework. Cutting and sorting was then used to process and organise the interview data into thematic categories, and to identify supporting statements that related to the identified themes. Verbatim quotes from the research participants' narratives were compiled. A compare and contrast approach was then used to identify similarities and differences among the different stakeholders' experiences. These were reorganised in the retelling of the narratives of how, as a collective, these stakeholders experienced their involvement with service users and carers in social work students' assessments.

\section{The findings}

The findings are reported under the key theme, 'Assessment as a site of power'. Each stakeholder group's perspective was explored within this theme. Participants' narratives are presented with some illustrative quotes to allow comparison to be made between groups. Pseudonyms are used and any identifying information was removed.

\section{Service users and carers' narratives}

Participants' narratives indicated that although service users are given a voice in social work students' assessments, they felt they had less influence than social work academics regarding summative assessment decisions. In this extract Julie describes her experience as a carer assessor at a university-based Practice Assessment Panel:

.... if we're quiet, the chair will always say 'What do the service users think about that?' So our feedback is always there, even if we are not very forthcoming and don't know what to say.

Julie's story indicates that carers are given a voice in students' assessments. However, as her story unfolded, she revealed different power relationships between social work academics and carers at the important formal panel meetings that decide whether the student will progress to the next stage: 
...but what will happen is that at the (panel) you will have two people [service users] looking at each portfolio and if it's a fail, they [portfolio] very often go to the academics to look at that... what is good is when their [student's portfolio] is looked at by the academics, their comments will be heard by the whole (panel).

Julie's narrative suggested ambivalence about the power to fail students. It also seems to imply that carers' comments would not be heard by the whole panel. When asked why carers would want social work academics to support the carer's fail recommendation, she responded:

...I think a lot of service users know what to say but they don't know how to say it...my feeling is that they [academics] would be able to express the underlying issues with a failed student better to the whole group.

Others expressed similar concerns. When Janet, a service user assessor, was asked whether she could influence summative assessment decisions alongside social work employers as coassessors, she responded:

Well, I can't see that happening... we don't have the power.

Janet indicated that some staff members had initially resisted the idea of service user involvement in assessments at her institution:

...we have had a certain amount of resistance from one or more members of staff, although the majority are very keen for us to be involved.

Similarly, Charles, a carer, revealed that although carer involvement in students' assessments is accepted, some staff members had initially resisted this: 
Some people, in the early days, did used to resent our involvement but now, almost exclusively, that doesn't happen. I think we are definitely feeling valued by the [institution], certainly with regard to our involvement in assessments.

\section{Social work educators' narratives}

Social work educators' narratives revealed complex power dynamics, tensions, dilemmas, conflicts and ambivalent feelings towards service user involvement in social work students' assessments.

James provided insights into the positioning of service users in social work students' assessments:

I think with all service user things it tends to be tagged on...You hear it all the timeoh, we better ask a service user - you hear it in meetings. You talk about the business and then someone will say 'Oh, what about the service users' and someone else will say 'We'd better ask them'. It's a bit of an afterthought.

James' narrative highlights some challenges of service user involvement in students' assessments:

I remember one example where the applicant used what the tutor felt was homophobic language. Now, the service user didn't pick that up, didn't think that was a problem, thought they'd be great. We've got this sort of set of requirements that we are aware of about values, about standards, about boundaries. How do we expect service users just to come into our world and be free to express themselves?

James' comments were echoed by Victoria, who reported on an experience of involving a service user in student assessments at a different institution: 
... a number of generalisations about races and cultures and things like that and it kind of gave the students the opportunity to discredit everything that she [service user] was saying because of the manner in which it was delivered.

When asked how best to address the experience described here, Victoria replied:

I don't want to start by 'training' service users, because you lose the essence of the genuine message, but they really need to learn about delivery, especially within a professional programme.

James went on to discuss what he perceived to be another problem relating to service user involvement in student assessments:

The other problem that I've found... we've used a group of service users from a local voluntary agency over several years. They became very comfortable coming in and after a while, you could hear that they began to talk like us.

\section{Social work students' narratives}

In contrast to the social work educators' narratives, the students' narratives, including those undertaking the Newly Qualified Social Work (NQSW) programme of study, centred on the challenges of obtaining service user and carer feedback in certain areas of social work practice, and the implications of failing an assessment. Like the social work educators, the NQSWs expressed ambivalent feelings about service user involvement in assessments. Summer said:

...I think for me the feedback I took more seriously was the feedback I got from my on-site assessor and there are things in my mind that she said to me that I've never forgotten and have really impacted on my practice.

Jonathan, a Masters student, also indicated that he valued his practice assessor's assessment feedback more than that of the service user: 
...when I consider the service user's feedback and the practice assessor's contribution to my progress, I think that the assessor's one carries more weight.

Jonathan described his experience of seeking service user feedback:

...Most of them can't write.

Jonathan's comments were echoed by April who described her experiences of seeking service user feedback during her NQSW training:

...people don't know what to write. With academic forms and the way the forms are written sometimes, they're not easy, not plain English, some of the boxes are hard to fill in.

These narratives draw attention to how the process of seeking service user feedback could inhibit some service users in contributing to student assessments.

In this excerpt Summer discussed the potential dilemmas and challenges of involving service users from child protection social work in student assessments. Her narrative centred on procedural fairness:

...I'm trying to think about the fairness of it all. If you've got someone working in a voluntary agency, they are a social worker in that agency but in more of a helping role, the feedback from the service user is going to be far more positive, whereas working in a statutory agency where the threat is that you're going to remove someone's children, the feedback may not be so cordial and could that result in a student passing or failing.

\section{Social work employers' narratives}

The employers' narratives suggested that they appreciated the principles of service user involvement in students' assessments. Margaret, a social work manager, acknowledged the importance of service user feedback: 
...I think service user feedback is very important......I suppose if they are saying something like, 'Oh my God, that person's awful. I wouldn't let them look after my cat never mind my mother!' then they do have something important to say.

The involvement of service users in social work students' assessments in palliative care settings was confirmed by Camilla, a manager:

We've just had a student who has just finished here and he got service user feedback. The service users had to fill in a form. He got glowing feedback, as did the student last year and I think they [service users] enjoyed filling in the forms saying how they felt.

Vanessa, another social work manager, highlighted the importance of carer feedback:

I think carer feedback is very, very important. In some ways it has been neglected in the past... we are very often closed in at looking at service user feedback. I think that has to be broadened.

When asked whether service users would be able to fail a student, Camilla said:

I don't think so, do you? I can't imagine they will. I mean the truth is, it's not that easy for a student to fail. ... I think it would be ever so hard for service users to be part of the process of passing or failing, it just wouldn't happen.

Some questioned the rationale for involving service users in students' assessments:

We need to be clear about what we hope to gain from service users being involved in assessment and what part of assessment would they be involved in. (Natasha, social work manager)

\section{Discussion}

Bourdieu's (1990) concepts of capital and doxa provide a useful framework for understanding the structural relations between service users and others involved in assessing 
students. They also provide a lens through which to conceptualise possible ways forward. Bourdieu (1990) discusses four interconnected forms of capital: cultural, social, economic and symbolic capital. The concept of cultural capital relates to the acquisition or possession of specialist knowledge gained through experiences, education and/or training. Social capital relates to networking, whilst economic capital refers to wealth defined in either monetary terms or financial resources. Symbolic capital consists of power, authority and prestige. The concept of doxa is underpinned by symbolic power and can be thought of as a taken-forgranted unquestioned rule, know-how or what Bourdieu (1990) refers to as 'the rules of the game'. The discourse which validates service user and carer involvement in assessing students is based on notions of expert by experience. This centres on personal knowledge gained through using social work services; this is different knowledge. The challenges associated with completing student assessment feedback, and or delivering feedback as well as navigating through complex HEI assessment systems and structures are not acknowledged within this discourse. The interview data indicated that some service users are unable to complete assessment feedback forms. As a doxa, HEI assessment systems and structures are unquestioned and unchallenged. Although service users' past experience as recipients of social work services enables them to participate in students' assessments, symbolic capital, which consists of prestige positions, appears to be accorded to social work educators both at the academy and in practice. The interview data obtained from service users raises important questions about whether they have the confidence and power to make informed decisions about passing or failing students.

Consistent with previous studies, the narratives revealed that although service users had been given a voice in students' assessments (Dearnley et al., 2011; Debyser et al., 2011; Duffy et al., 2013; Muir and Laxton, 2012; Skilton, 2011; Skoura-Kirk et al., 2013; Stacey et al., 2012; Stickley et al., 2010; 2011), summative assessment decisions that affect progression remained with social work academics (Skilton 2011; Skoura-Kirk et al., 2013). The study findings, albeit with a small sample, concur with prior research in relation to both academic and practice assessments of students. The findings revealed contrasting ways in which the research participants had experienced the involvement of service users in assessment and some tensions within these relationships. Although all the research participants identified with the goal of service user involvement, there were clear differences in their narratives, 
depending on their positions. Interview data showed that service users wanted to 'give something back', social work educators reported tensions and contradictions about the processes of involvement, and students focused on implications for their progression. Additionally, the data suggested some students valued their practice educators or tutors' feedback more than that of service users. Furthermore, tensions and dilemmas regarding involvement were highlighted by social work educators, employers and students' participants. Most identified the issue of delivering effective feedback, and a perceived lack of expertise and skills by service users, as areas of concern, echoing Muir and Laxton (2012) and Webster et al. (2012). The findings also suggest that there are undoubted challenges in obtaining a fair assessment in settings, such as child protection social work. For example, there were concerns that service users may abuse their powers as assessors in order to express their dissatisfaction with the system.

\section{A way forward}

The importance of training assessors in social work students' assessments was raised by Bogo et al. $(2011$; 2012) in their North American study, although this does not refer specifically to training service users. In the UK context at the time of writing, UNTRAP, a service user organisation in partnership with the Centre for Life Long Learning at the University of Warwick, Coventry (UK), offered an accredited training programme for service user involvement in teaching and research. The module content included presentation skills, assessment and feedback, and was led by Warwick Medical School (Jørgensen et al., 2013). In the context of service user involvement in students' assessments, Muir and Laxton (2012), Skilton (2011), Skoura-Kirk et al. (2013) and Webster et al. (2012) all reported on providing training and support. These studies suggested that service users developed confidence in delivering feedback following the training.

Although service users who took part in this study did not specifically ask for training and support, HEIs and social work employers interested in developing service user involvement in students' assessments could offer assessor training. (Training, rather than education, is used here because it is the term most commonly used within the literature on service user and carer involvement.) Social work students' assessment systems and structures, and the balance 
of power as a doxa, could be demystified by providing training for service users and carers to enable them to design and deliver students assessment feedback on both practice and academic work as well as on how to navigate through HEI assessment systems. This would address some of the unequal power relations between social work professionals and service users, as well as improve relationships with service user organisations.

In order to avoid losing the authentic voice and essence of what service users bring to students' assessments, this training could be delivered by service user assessors who have participated in students' assessments and have gained skills and confidence in this area. Service user organisations, such as Shaping Our Lives, could provide the strategic support needed to facilitate education and training programmes, for example, by bringing together social work educators and service users who wish to be involved in the assessment of students. Whilst this could arguably go some way to support service users, there is undoubtedly a danger that this could produce service user and carers who although are suitable for assessing students would not necessarily reflect the service user and carer population that students are likely to meet in practice. Yet without such training, social work educators could be accused of assuming that service users and carers have the know-how to design and deliver students assessment feedback on both practice and academic work as well as navigate through complex HEI assessment systems and structures. There are clear tensions here and the issue requires critical analysis, to ensure that the authentic voice of service user and carer assessors is retained during training to enable them to contribute to students' assessments on equal terms. They might need training, for example, in addressing discrimination and oppression.

However, the issue of resourcing service user involvement in social work education continues to be contentious (DH, 2014; Sadd, 2011). At the time of writing, service user involvement was funded in England by the government and administered by the NHS Business Services Authority (DH, 2014). Croisdale-Appleby's (2014) independent review of social work education reported that funding for service user involvement was relatively small (HEIs were paid a block grant of $£ 7,400$ per course).

\section{Concluding comments}


There are clear limitations to the study due to its sample size, and qualitative generalisation cannot be made to other populations. However, variation-based generalisation can be made. Smaling (2003) describes variation-based generalisation as the use of different sample groups for variation purposes. A potential advantage of this study compared to others is that it addressed the perspectives of a range of stakeholders, including social work students, service users, carers, social work educators and social work employers.

The study's findings indicate that service users and carers have been given a voice in both formative and summative assessments of social work students. Consistent with other studies, it suggests that the final assessment decision still rests with social work academics, rather than with service users and carers. The findings also identify the need for training those involved in assessment. Social work as a profession has a role in supporting service users to contribute to the assessment of students' work. This can be sustained by continuing to support them with the funding and resources needed to provide such training programmes. This may help address some of the identified tensions between social work educators and service users, as well as improve relationships with service users. Similar to the training for service users, such support should be extended to social work educators and practitioners on how to engage meaningfully with service users in students' assessments. Research could be undertaken to evaluate the effectiveness of such training and provide further insights into how partnership arrangements between service users and social work educators and universities are working.

\section{References}

Askheim, O. P. (2012). 'Meeting Face to Face Creates New Insights': Recruiting Persons with User Experiences as Students in an Educational Programme in Social Work, Social Work Education: The International Journal, 31:5, 557-569. doi:10.1080/02615479.2011.590972

Australian Association of Social Workers (2012). Australian Social Work Education and Accreditation Standards (ASWEAS) ASWEAS 2012 V1.4 Revised January 2015. Canberra: Australian Association of Social Workers

Barnes, M., \& Cotterell, P. (2012). From margin to mainstream. In M. Barnes \& P. Cotterell 
(Eds.) Critical Perspectives on User Involvement (xv-xxvi). Bristol: The Policy Press Beresford, P. (2013). Interprofessional and Interagency Working: Service users, carers and different professional groups. In B. Littlechild\& R. Smith (Eds.) A Handbook for Interprofessional Practice in the Human Services: Learning to work together (pp. 187-199). Harlow: Pearson Education Ltd

Bogo, M., Regehr, C., Logie, C., Katz, E., Mylopoulos, M., \& Regehr, G. (2011). Adapting objective structured clinical examinations to assess social work students' performance and Reflections. Journal of Social Work Education, 47:1, 5-18

Bogo, M., Regehr, C., Katz, E., Logie, C., Tufford, L., \& Litvack, A. (2012). Evaluating an Objective Structured Clinical Examination (OSCE) Adapted for Social Work. Research on Social Work Practice, 22: 4, 428-436. doi: 10.1177/1049731512437557

Boud, D. (1996). Enhanced Learning Through Self-Assessment. London: Kogan Page.

Boulton, M. (2009). Research ethics. In J. Neal (Ed.) Research methods for health and social care (pp. 31-45). Basingstoke: Palgrave

Bourdieu, P. (1990). The logic of practice. Cambridge: Polity Press

Broadfoot, P. (Ed.) (1984). Selection, Certification and Control: Social Issues in Educational Assessment. London: Falmer.

Brown, L., M., \& Gilligan, C. (1992). Meeting at the Crossroads: Women's Psychology and Girls’ Development. Cambridge, Massachusetts: Harvard University Press

Chambers, M., \& Hickey, G. (2012). Service user involvement in the design and delivery of education and training programmes leading to registration with the Health Professions Council. London: Kingston University and St George's, University of London

Council on Social Work Education (CSWE) (2013). Educational policy and Accreditation Standards. Retrieved from http://www.cswe.org/File.aspx?id=41861

Croisdale-Appleby, D. (2014). Re-visioning social work education: An Independent Review. Retrieved from https://www.gov.uk/government/uploads/system/uploads/attachment_data/file/285788 /DCA_Accessible.pdf

Dearnley, C., Coulby, C., Rhodes, C., Taylor, J., \& Coates, C. (2011). Service users and carers: preparing to be involved in work-based practice assessment, Innovations in Education and Teaching International, 48:2, 213-222. doi: $10.1080 / 14703297.2011 .564020$ 
Debyser, B., Grypdonck M., H., F., Defloor, T., \& Verhaeghe, S. L. (2011). Involvement of inpatient mental health clients in the practical training and assessment of mental health nursing students: Can it benefit clients and students. Nurse Education Today, 31,198-203

Department of Health (DoH) (2002). Requirement for Social Work Training. London: DoH Department of Health (DH) (2014). Reforming the Education Support Grant: The Government Response to the Consultation. London: HMSO

Drake, P., \& Heath, L. (2011). Practitioner Researcher at Doctoral Level: Developing Coherent Research Methodologies. London: Routledge

Duffy, J., Das, C., \& Davidson, G. (2013). Service User and Carer Involvement in Role-plays to Assess Readiness for Practice. Social Work Education - The International Journal, 32:1, 39-54. doi: 10.1080/02615479.2011.639066.

Fairtlough, A., Bernard, C., Fletcher, J., \& Ahmet, A. (2013a). Experiences of Lesbian, Gay and Bisexual Students on Social Work Programmes: Developing a Framework for Educational Practice. British Journal of Social Work, 43:3, 467-485. doi: 10.1093/bjsw/bcs001

Fairtlough, A., Bernard, C., Fletcher, J., \& Ahmet, A. (2013b). Black social work students' experiences of practice learning: Understanding differential progression rates. Journal of Social Work, 14:6, 605-624. doi: 10.1177/1468017313500416

Gilligan, C. (1982). In a Different Voice: Psychological Theory and Women's Development. Cambridge. Harvard: University Press

Health and Care Professions Council (HCPC) (2012). Service user involvement in the design and delivery of education and training programmes leading to registration with the HCPC. London: HCPC

Houghton, C. E., Galway, D. C., Galway, D. S., \& Murphy, K. (2010). Ethical challenges in qualitative research: examples from practice. Nurse Researcher, 18: 1, 15-25. Retrieved from http://dx.doi.org/10.7748/nr2010.10.18.1.15.c8044

Jørgensen, C. R., Blaxter, L., Purkis, J., Tulip, S., Lunn, S. Hundt, G. L. with UNTRAP (2013). Accredited Training in User-Involvement: Impact, Challenges and Ways Forward. Warwick Medical School, University of Warwick. Retrieved from http://www2.warwick.ac.uk/fac/cross_fac/healthatwarwick/untrap/newsandupdates/po $\underline{\text { ster_exeter_1.pdf }}$

Kvarnström, S., Willumsen, E., Andersson-Gare, B., \& Hedberg, B. (2012). How Service 
Users Perceive the Concept of Participation, specifically in Interprofessional Practice. British Journal of Social Work, 42: 1, 129-146. doi: 10.1093/bjsw/bcr049

Kvarnström, S., Hedberg, B., \& Cedersund, E. (2013). The dual faces of service user participation: Implications for empowerment processes in interprofessional practice. Journal of Social Work, 13: 3, 287-307. doi: 10.1177/1468017311433234

Mauthner, N., \& Doucet, A. (1998). Reflections on a voice-centred relational method: Analysing maternal and domestic voices. In J, Ribbens \& R. Edwards. (Eds.) Feminist Dilemmas in Qualitative Research. London: Sage. Retrieved from http://http-server.carleton.ca/ adoucet/pdfs/Mauthner_Doucet_Voice_1998.pdf

McLaughlin, H. (2009). What's in a Name: 'Client', 'Patient', 'Customer', 'Consumer', 'Expert by Experience', 'Service User'—What's Next? British Journal of Social Work, 39: 6, 1101-1117. doi: 10.1093/bjsw/bcm155

Mercer, J. (2007). The challenges of insider research in educational institutions: wielding a double-edged sword and resolving delicate dilemmas. Oxford Review of Education, 33:1, 1-17. doi: 10.1080/03054980601094651

Muir, D., \& Laxton, J. C. (2012). Experts by experience; the views of service user educators providing feedback on medical students work based assessments. Nurse Education Today, 32, 146-150

Munro, J. Whyte, F., Stewart, J., \& Letters, A. (2012). Patients assessing students' assignments; Making the patient experience real. Nurse Education Today, $32,139-145$

Patton, M. Q. (2002). Qualitative Research and Evaluation Methods, third edition. London: Sage

Reinders, M. E., Blankenstein, A. H., E., Van Der Horst, M., Knol, D., L., Schoonheim, P., L., \& Van Marwijk, H., W., J. (2011). Does patient feedback improve the consultation skills of general practice trainees? A controlled trial. Medical Education, 44, 156-164. doi 10.111/j.1365-2923.2009.03569.x

Riessman, C. K., \&Quinney, L. (2005). Narrative in Social Work: A Critical Review. Qualitative Social Work, 4: 4, 391-412. doi: 10.1177/1473325005058643

Robinson, K., \& Webber, M. (2013). Models and Effectiveness of Service User and Carer Involvement in Social Work Education: A Literature Review. British Journal of Social Work, 43: 5, 925-944. doi: 10.1093/bjsw/bcs025

Ryan, G.W., \& Bernard, H.R. (2003). Techniques to Identify Themes. Field 
Methods, 15: 1, 85-109. doi: 10.1177/1525822X02239569

Sadd, J. (2011). 'We are more than our story': service user and carer participation in social work education. SCIE: London

Skilton, C. J. (2011). Involving Experts by Experience in Assessing Students' Readiness to Practise: The Value of Experiential Learning in Student Reflection and Preparation for Practice. Social Work Education: The International Journal, 30: 03, 299-311. doi:10.1080/02615479.2010.482982

Skoura-Kirk, E., Backhouse, B., Bennison, G., Cecil, B., Keeler, J., Talbot, D., \& Watch, L. (2013). Mark my words! Service user and care involvement in academic assessment. Social Work Education: The International Journal, 32: 5, 560-575. doi: $10.1080 / 02615479.2012 .690388$

Smaling, A. (2003). Inductive, analogical, and communicative generalization. International Journal of Qualitative Methods, 2: 1, 52-67. Retrieved from (http://creativecommons.org/licenses/by/2.0)

Smith, M., Gallagher, M., Wosu, H., Stewart, J., Cree, V. E., Hunter, S., \& Evans, S. (2012). Engaging with Involuntary Service Users in Social Work: Findings from a Knowledge Exchange Project. British Journal of Social Work, 42: 8, 1460147. doi: $10.1093 / \mathrm{bjsw} / \mathrm{bcr} 162$

Squire, C. (2008). Approaches to Narrative Research, NCRM Review Papers. London: ESRC National Centre for Research

Stacey, G., Stickley, T., \& Rush, B. (2012). Service user involvement in the assessment of student nurses: A note of caution. Nurse Education Today, 32, 482-484

Stickley, T. (2006). Should service user involvement be consigned to history? A critical realist perspective. Journal of Psychiatric and Mental Health Nursing, 13: 5, 570-577. doi:10.1111/j.1365-2850.2006.00982.x.

Stickley, T., Stacey, G., Pollock, K., Smith, A., Betinis, J., \& Fairbank, S. (2010). 'The practice assessment of student nurses by people who use mental health services'. Nurse Education Today, 30, 20-25

Stickley, T., Stacey, G., Pollock, K., Smith, A., Betinis, J., \& Fairbank, S. (2011).

'Developing a service user designed tool for the assessment of student mental health nurses in practice: A collaborative process. Nurse Education Today, 31, 102-106

Taylor, I. (1997). Developing learning in Professional Education: Partnerships for 
practice. Buckingham: The Society for Research into Higher Education and Open University Press

Taylor, I., Braye, S., \& Cheng, A. (2009). Carers as Partners (CaPs) in social work education. London: SCIE

Taylor, J. M., Gilligan, C., \& Sullivan, A. M. (1995). Between Voice and Silence: Women and Girls, Race and Relationship. Cambridge, Massachusetts: Harvard University Press

Wallcraft, J., Fleischmann, P., \& Schofield, P. (2012). The involvement of users and carers in social work education: a practice benchmarking study. London: SCIE

Webber, M., \& Robinson, K. (2012). The meaningful involvement of service users and carers in advanced-level post-qualifying social work education: A qualitative study. British Journal of Social Work, 42, 7, 1256-1274. doi:10.1093/bjsw/bcr141

Webster, B. J., Goodhand, K., Haith, M., \& Unwin, R. (2012). The development of service users in the provision of verbal feedback to student nurses in a clinical simulation environment. Nurse Education Today, 32, 133-138 